Available online on 15.02.2020 at http://jddtonline.info
Open Access to Pharmaceutical and Medical Research
unrestricted non-commercial use, provided the original work is properly cited

Open Access

Research Article

\title{
The Phytochemical and Comparative Anticancer Study of Methanolic and Chloroform Extracts of Psidium guajava L. Leaves of Pakistani Origin
}

\author{
Abbas Muhammad ${ }^{*}$, Ansari Muhammad Tayyab ${ }^{2}$, Saeed ul Hassan ${ }^{3}$, Alvi Muhammad Nadeem ${ }^{4}$, Abbas \\ Musharraf ${ }^{5}$ \\ ${ }^{1 *}$ Assistant Professor, Islam College of Pharmacy, Sialkot, Pakistan \\ 2 Professor, Department of Pharmaceutical Chemistry, Bahauddin Zakariya University, Multan, Pakistan \\ ${ }^{3}$ Professor, Faculty of Pharmacy, University of Lahore, Lahore, Pakistan \\ ${ }^{4}$ Assistant Professor, Faculty of Pharmacy, University of Central Punjab, Lahore, Pakistan \\ ${ }^{5}$ Lecturer, Lahore Pharmacy College, Lahore, Pakistan
}

\section{ABSTRACT}

The chief focus of our study is to evaluate the phytochemical and anti-cancer activity of methanol (PGM) and chloroform extracts (PGC) of the leaves of Psidium guajava (guava) collected from local area of district Sialkot, Pakistan. Shade dried milled leaves was subjected to extraction (maceration) with methanol and chloroform. Quantitative and qualitative screenings by GC-MS and phytochemical techniques were performed. Then different secondary metabolites and phytochemical compounds were identified which are typically associated with the existence of therapeutic characteristics. Psidium guajava has been extensively used as herbal remedies like, anti-diarrheal, antihypertensive, antibacterial, antifungal as well as to control obesity, ulcer, diabetes. In this study, both extracts of P. guajava were evaluated for their anticancer activities against HeLa cell-lines (cancerous cells). The healthiest anticancer response in the form of cell-line suppression was perceived with $200 \mu \mathrm{g} / \mathrm{mL}$ of both extracts, PGM showed $81 \%$ and PGC exhibited $91 \%$ while the standard drug doxorubicin presented around $76 \%$ inhibition. The comparative better result was seen with chloroform extract than methanolic abstract. In conclusion, the chloroform and methan ol extracts of our nominated plant from Pakistan origin has a good source of phytochemicals that revealed an outstanding anti-cancer potential.
\end{abstract}

Keywords: Psidium guajava, anticancer, phytochemicals, methanol extracts, secondary metabolites.

Article Info: Received 21 Nov 2019; Review Completed 12 Jan 2020; Accepted 26 Jan 2020; Available online 15 Feb 2020

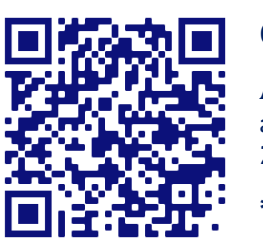

Cite this article as:

Abbas M, Ansari MT, Saeed UH, Alvi MN, Abbas M, The Phytochemical and Comparative Anticancer Study of Methanolic and Chloroform Extracts of Psidium guajava L. Leaves of Pakistani Origin, Journal of Drug Delivery and Therapeutics. 2020; 10(1-s):149-153 http://dx.doi.org/10.22270/jddt.v10i1-s.3922

Muhammad Abbas, Islam College of Pharmacy, Pasrur Road, Sialkot-51040, Pakistan

\section{INTRODUCTION}

Natural compounds obtained from animal and plant sources have been used to treat various diseases of human being earlier around $6000 \mathrm{BC}$. It is strongly believe that natural plants still have a strong therapeutic benefits and providing a foundation for the isolation and synthesis of novel medicinal compounds. According to the assessment of WHO, more than $80 \%$ of the world population trusted on herbal medication on primary health care level. Regarding the management of chronic and acute illness in China, Pakistan and India, the tradition herbs also have a significant role ${ }^{1}$. Leaves of Psidium guajava have incredible significance to manage the various diseases worldwide with better patient compliance when compared to the allopathic system of treatment. Psidium guajava belongs to Myrtaceae family and its plant around 20 -feet long. Leaves are 05 to $15 \mathrm{~cm}$ long having bulging pinnate veins and oval blade like shape. It is preferably grown in dry weather and extensively cultivated in tropical/subtropical parts of the world including; Asia,
Europe, Africa, America and Mexican region. P. guajava tagged by various nations such as; amrood in Pakistan, banjiro in Japan, goiabeiro in Portugal, goyave in France, guava in English and guayave in German². Traditionally, different parts of guava have been recommended for the treatment of wounds, lesions, ulcers, diarrhea, cholera, hypertension, obesity and control of Diabetes mellitus ${ }^{3}$. Antibacterial, antioxidant, leishmanicidal, and hepatoprotective properties have seen in leaves of this plant 4 . Through GC-MS analysis and phytochemical techniques, various compounds were identified from the methanol and chloroform extracts of P. guajava.

The mortality rate with cancer is high in both developed and under-developed countries worldwide, because of population growth and age seniority besides embracing cancer triggering activities 5 . Treatment of cancers particularly the solid cancers have been treated conventionally by chemotherapy, surgically removing and radiation therapy, with a bit less success rate6. In addition 
conventional chemotherapeutic compounds were found to be not only toxic and inhibit the growth of cancerous cells but also have a drastic effect on the progress of normal cells in the body7. Products from natural sources on the other hand, comparatively harmless and biologically compatible to the living tissues ${ }^{8}$. Hence, the natural plants have become a prime goal for the exploration and recognition of novel anticancer medicine9. Though the anticancer activities of essential oils, polysaccharides and other extracts in various parts of Psidium guajava was studied, but limited studies and assessment were performed on the real potential of guava leaves from indigenous area of Pakistan origin. Since, our study was mainly focused on the evaluation of anticancer activity of methanol and chloroform extracts of Psidium guajava leaves because of easy access of everybody in our region. In addition, comparative anticancer potential of methanol and chloroform extracts was also done and superior antitumor response was seen with our extracts.

\section{MATERIALS AND METHODS}

\section{Plant Collection}

Fresh leaves of Psidium guajava were collected from the main Orchard besides Sialkot International Airport, Sialkot, Pakistan. Plant sample was deposited and obtained Voucher Specimen No. GC-Herb-Bot-2408 after identification from the Dr. Sultan Ahmed Herbarium, Department of Botany, Government College University, Lahore, Pakistan.

\section{Drying and Extraction}

After collection of leaves of $P$. guajava were shad dried for the period of fortnight and made course powder with grinder. Extraction of plant material was done through maceration with methanol and chloroform. About 05-liter analytical grade methanol (Sigma made in Australia) was used for the maceration of $01-\mathrm{Kg}$ powder of plant in glass pot with vigorous mechanical stirring twice daily for 01 week at room temperature. Then, muslin cloth was used to filter the mixture and filtrate was passed through Whatman filter paper grade 01 (Sigma-Aldrich). The Rotary Evaporator (IKA HB10 Basic, Made in Germany) was used to achieve the concentrated dry masses from the filtrate at $35 \pm 5^{\circ} \mathrm{C}$ under reduced pressure. Resulting \% age yield of methanolic extract of $P$. guajava (PGM) was found $8.4 \%$ and stored at $04^{\circ} \mathrm{C}$ in refrigerator for the further investigations ${ }^{\mathbf{1 0}}$.
Residual material after extraction with methanol was dried, weighed (991 g) and macerated for 01-Wk in glass bottle with 05-L chloroform (MERCK) analytical grade. Mixture was filtered and dried as done with methanol method. The resulting semisolid material (3.2\% Yield) was obtained, assigned code PGC and stored in well closed flask $\left(04^{\circ} \mathrm{C}\right)$.

\section{Phytochemical studies}

The phytochemical investigation of crude powder of plant was performed and recognized the existence of phytochemical constituents of various classes such as; alkaloids, anthraqinones, catechins, flavonoids, phenolic compounds, saponins, steroids and tannins ${ }^{\mathbf{1 1}}$.

\section{GC-MS Analysis}

Eight different compounds were identified from methanolic extracts of $P$. guajava using GC-MS Agilent Technologies (GC Model: 7890A, MS Model: $5975 \mathrm{C}$ ). The ${ }^{\circ} \mathrm{GC}-\mathrm{MS}$ protocol ${ }^{\circ}$ was employed with slight temperature modification ${ }^{12}$. At the start, temperature was adjusted at $110^{\circ} \mathrm{C}$ for 02 minutes and continually raised at the rate of $10^{\circ} \mathrm{C}$ per min up-to $280^{\circ} \mathrm{C}$.

\section{Anticancer Activity}

\section{Method of analysis}

Anticancer activity of methanolic (PGM) and chloroform (PGC) extracts of Psidium guajava was evaluated in our study. Bioassay protocol was employed as; firstly Dulbecco's Eagle medium was modified with $10 \%$ foetal bovine serum in $75 \mathrm{ml}$ flask. Then medium was inoculated with HeLa cellline (cervical carcinoma) by incubating at $37^{\circ} \mathrm{C}$ in the presence of $5 \% \mathrm{CO}_{2}$. The confluence after collection was planted in 96-well plates pre-treated with tissue culture. After around 24-hour incubation of well plates, methanol and chloroform crude extracts of $P$. guajava were added in doses of $50 \mu \mathrm{g}, 100 \mu \mathrm{g}$ and $200 \mu \mathrm{g} / \mathrm{mL}$ each in triplicate and made incubation for the period of 48-hour. The positive standard drug doxorubicin was used in MTT assay along $200 \mu \mathrm{l}$ MTT at the dose of $50 \mu \mathrm{g} / \mathrm{mL}$. Then added into wells of test chamber and incubated around 03 hours at $37^{\circ} \mathrm{C}$. The tetrazolium salt was reduced to form formazan crystals after specified time of incubation period. Then solution of crystals was made by dissolving them in $100 \mu \mathrm{L}$ of DMSO. The absorbance was measured at 570-nm with the help of microplate reader ${ }^{13}$. The percentage inhibition or suppression of viable cells was determined by using following formula.

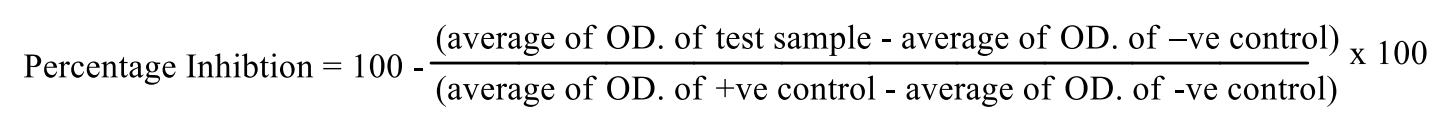

\section{Study of Acute Toxicity on Healthy Animal}

Three groups of healthy Sprague Dawley rats were made after 12-hr fasting and each group have had 05-rats. First group was given orally $750 \mathrm{mg} / \mathrm{kg}$ of methanol extract (PGM) and $2^{\text {nd }}$ group was administered $750 \mathrm{mg} / \mathrm{kg}$ extract of chloroform (PGC). Third one was nominated as control who received only $10 \%$ DMSO. After 4-hr, 24-hr and 168-hr administration of extracts, signs and symptoms were observed. There was no any toxic sign like mortality and morbidity was noticed in any animal.

\section{Statistical Analysis}

Data was presented using Mean \pm SEM and analyzed through Graph-Pad PRISM (5.02). The quantitative variable comparison was intended with One-Way ANOVA followed by Tukey's multiple comparison 'Student's t-test ${ }^{\circ}$. The P value $\leq$ 0.05 was considered as statistically significant.

\section{The comparative anticancer potential of two extracts}

The comparative anticancer activity of both extracts PGM and PGC with different concentration was evaluated and found chloroform extract had comparatively better control of cancer cells suppression than methanol extract of $P$. guajava.

\section{RESULTS}

\section{Phytochemical Screening}

The qualitative phytochemical screening of the crude powder of both plants was done in Department of Pharmaceutical Chemistry, Faculty of Pharmacy, Bahauddin Zakariy University, Multan, Punjab, Pakistan. The final outcomes were acknowledged in the Table 111,14. 
Table 1: Phytochemical screening (Qualitative) of Crude Powder of P. guajava

\begin{tabular}{|l|c|c|c|}
\hline \multicolumn{1}{|}{ S\# } & Phytochemicals & Test & Result \\
\hline 1. & Alkaloids & Dragendorff's & + \\
\hline 2. & Anthraquinones & Magnesium acetate & + \\
\hline 3. & Cardiac glycosides & Ferric chloride & + \\
\hline 4. & Flavonoids & Sodium hydroxide & + \\
\hline 5. & Saponins & Froth & + \\
\hline 6. & Steroids & Acetic anhydride & + \\
\hline 7. & Tannins & Ferric chloride & + \\
\hline
\end{tabular}

\section{GC-MS studies}

Through the use of ${ }^{\circ} \mathrm{GC}-\mathrm{MS}$ Agilent ${ }^{\circ}$ Technologies (GC Model: 7890A, MS Model: 5975C), 08-compound were identified from methanol extract of P. guajava (PGM) and enlisted with retention time, \%age content, chemical name, molecular formula, molecular weight and structural formula (Table 2).

Table 2: List of constituents in methanol extract of $P$. guajava identified by GC-MS

\begin{tabular}{|c|c|c|c|c|c|c|}
\hline Sr.\# & $\begin{array}{c}\mathbf{R}_{\mathbf{t}} \\
\text { (min) }\end{array}$ & Name of identified component & $\begin{array}{c}\% \text { of } \\
\text { content }\end{array}$ & $\begin{array}{l}\text { Mol.wt } \\
\text { g/mol }\end{array}$ & $\begin{array}{c}\text { Mol. } \\
\text { formula }\end{array}$ & Structure \\
\hline 1 & 11.100 & Copaene & 11.725 & 204 & $\mathrm{C}_{15} \mathrm{H}_{24}$ & \\
\hline 2 & 11.799 & Caryophyllene & 13.080 & 204 & $\mathrm{C}_{15} \mathrm{H}_{24}$ & \\
\hline 3 & 12.111 & 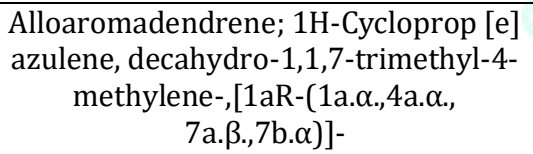 & 11.601 & 204 & $\mathrm{C}_{15} \mathrm{H}_{24}$ & \\
\hline 4 & 12.451 & Aromadendrene & 3.369 & 204 & $\mathrm{C}_{15} \mathrm{H}_{24}$ & \\
\hline 5 & 12.994 & $\begin{array}{c}\text { Valencene; Naphthalene, } \\
\text { 1,2,3,5,6,7,8,8a-octahydro-1,8a- } \\
\text { dimethyl-7-(1-methylethenyl)-,[1R- } \\
(1 . \alpha ., 7 . \beta, 8 \mathrm{a} . \alpha)]\end{array}$ & 1.845 & 204 & $\mathrm{C}_{15} \mathrm{H}_{24}$ & \\
\hline 6 & 13.387 & $\begin{array}{c}\delta \text {-Cadinene; Naphthalene, 1,2,3,5,6 } \\
\text { hexa,8a-hexahydro-4,7-dimethyl-1-(1- } \\
\text { methylethyl)-,(1S-cis)- }\end{array}$ & 3.712 & 204 & $\mathrm{C}_{15} \mathrm{H}_{24}$ & \\
\hline 7 & 14.406 & $\begin{array}{c}\text { Cyclopropa[d]naphthalene-2(4aH)-1, } \\
\text { 1,1a,5,6,7,8-hexahydro-4a,8,8- } \\
\left.\left.\text { trimethyl-,[1aR-(1a. } \alpha, 4 a . \beta, 8 a S^{*}\right)\right]-\end{array}$ & 2.530 & 204 & $\mathrm{C}_{14} \mathrm{H}_{20} \mathrm{O}$ & \\
\hline 8 & 27.623 & $\begin{array}{l}\text { Mono (2-ethylhexyl) phthalate; 1,2- } \\
\text { Benzenedicarboxylic acid, mono(2- } \\
\text { ethylhexyl) ester }\end{array}$ & 52.137 & 278 & $\mathrm{C}_{16} \mathrm{H}_{22} \mathrm{O}_{4}$ & \\
\hline
\end{tabular}




\section{Anticancer activity of Methanolic extract of Psidium guajava}

Methanol extract of PGM (50, 100 and $200 \mu \mathrm{g} / \mathrm{mL})$ was used for the evaluation of anticancer activity against HeLa cellline (ATCC \# HTB-22). The standard drug doxorubicin (50 $\mu \mathrm{g} / \mathrm{mL}$ ) was employed as positive standard. The inhibition of cell-lines were $20.32 \%, 44.30 \%$ and $81.28 \%$ seen with 50 , 100 and $200 \mu \mathrm{g} / \mathrm{mL}$ of extracts respectively as well as with doxorubicin (73.94\%). The significant response was observed with $100 \mu \mathrm{g} / \mathrm{mL}$ while the PGM $(200 \mu \mathrm{g} / \mathrm{mL})$ extract showed the excellent sign of inhibition on comparison to doxorubicin a standard drug (Figure 1).

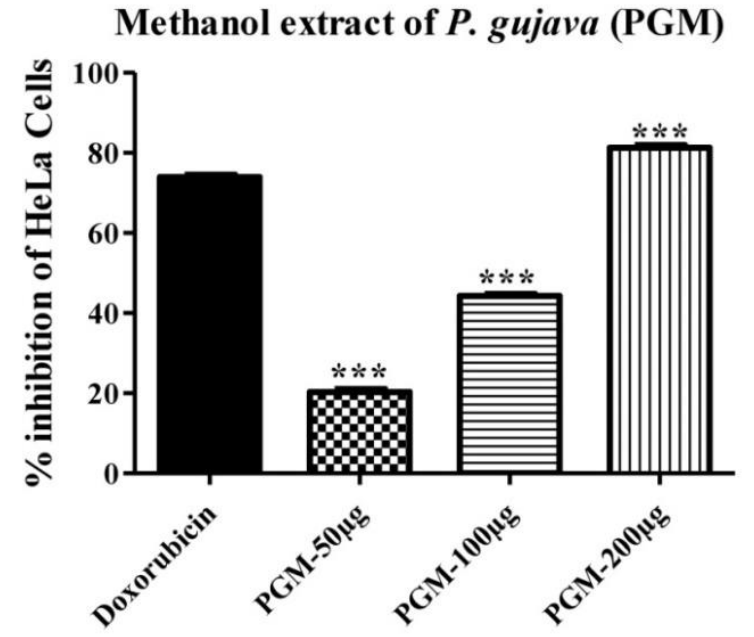

Fig. 1: The observation of significant suppression of HeLa cells with methanol extract of $\boldsymbol{P}$. guajava. Data presented the Mean \pm SEM, where ${ }^{*} \mathrm{P}<0.05,{ }^{* *} \mathrm{P}<0.01$ and ${ }^{* * *} \mathrm{P}<$ 0.001denoted the comparison of test groups with control

The anticancer potential of chloroform extract of $P$. guajava

The evaluation of anticancer activity of $50 \mu \mathrm{g}, 100 \mu \mathrm{g}$ and $200 \mu \mathrm{g}$ of chloroform extract of P. guajava was determined. The PGC extracts, $100 \mu \mathrm{g}$ and $200 \mu \mathrm{g}$ exhibited $52 \%$ and $91.67 \%$ suppression of HeLa cell-lines respectively. While doxorubicin showed $76 \%$ inhibition. We concluded that $200 \mu \mathrm{g}$ PGC extracts revealed a better antitumor potential when compared with standard drug (Figure 2).

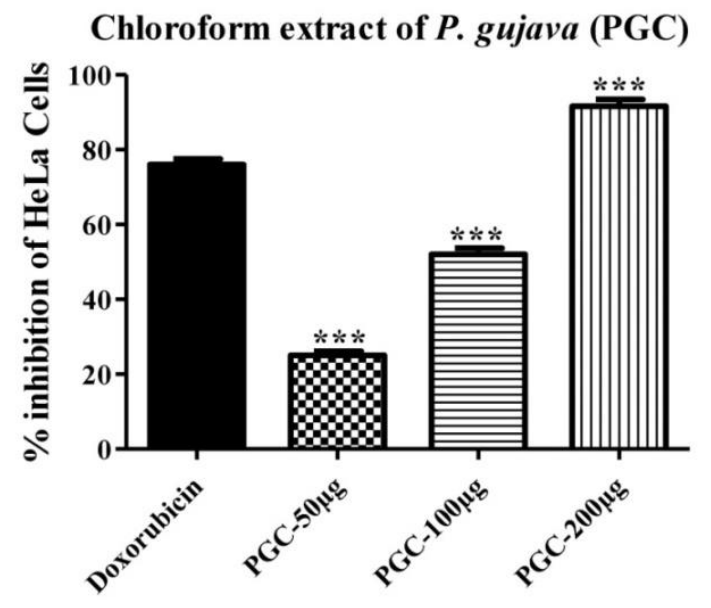

Fig. 2: The evaluation of chloroform extract of $P$. guajava against HeLa cell-lines. Data presented the Mean \pm SEM, where ${ }^{*} \mathrm{P}<0.05,{ }^{* *} \mathrm{P}<0.01$ and ${ }^{* *} \mathrm{P}<0.001$ showed the comparison of test groups with control

\section{Comparative anticancer activity of methanol and chloroform extracts of P. guajava}

When compared the anticancer activity of both extracts of $P$. guajava. Both extracts exhibited almost same rate of HeLa cells suppression. Chloroform extracts of P. guajava (PGC) with 50, 100 and $200 \mu \mathrm{g} / \mathrm{mL}$ doses showed 25, 52 and $91 \%$ inhibition respectively. While methanol extract (PGM) with same concentrations showed 20, 44 and $81 \%$ suppression respectively. Hence, chloroform extracts of guava showed bit better response than the methanol extract (Figure 3).

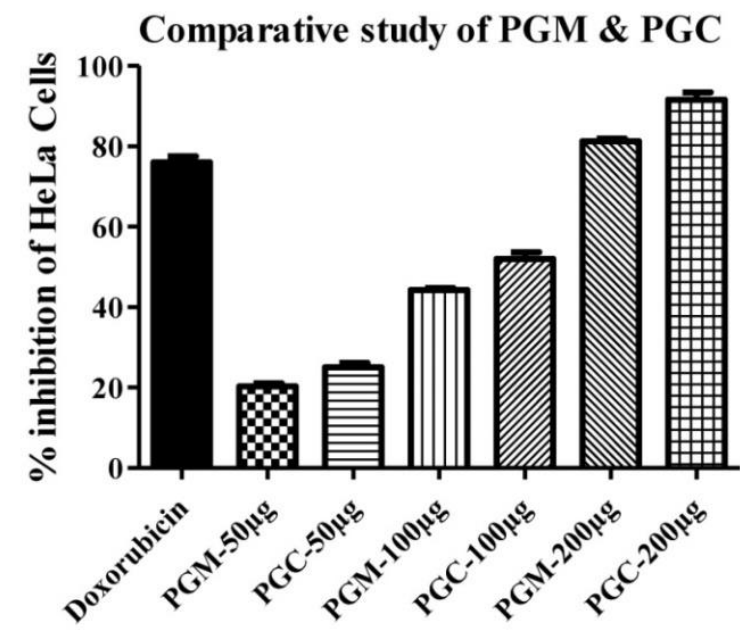

Fig. 3: The comparative anticancer activity of both plants evaluated and found PGC exhibited comparatively better response than methanolic extract

\section{DISCUSSION}

Thousands of herbal plants have been consuming all over the word to manage different diseases since ancient period. The current status of WHO report assumed that around $80 \%$ people worldwide are still relying on natural plant medicine on primary health-care levels. Phytochemical, chromatographic and spectroscopic screenings are always the initial steps on natural flora for the assessment of bioactivity and identification of bioactive compounds. Plants usually contained various kinds of compounds with diverse polarities relating to different rate of solubility. The methanol and chloroform extracts of $P$. guajava were selected for the qualitative phytochemical analysis and found different secondary metabolites such as; glycosides, flavonoids, alkaloids, saponins, anthraquinones and tannins. Secondary metabolites have a significant role to control various biological activities ${ }^{15}$. Likewise, it was also recognized that secondary-metabolite are effectively control the cancers and cancer related diseases ${ }^{16,17}$. The GC-MS analysis of methanol extract of $P$. guajava showed 08 different compounds. The recognized compounds in our extracts showed diverse proportions such as; Mono (2ethylhexyl) phthalate found in highest concentration (52\%) and $2^{\text {nd }}$ higher percentage contents of Caryophyllene, (13\%). The $3^{\text {rd }}$ high share of Copaene $(12 \%)$ and other big contents of Alloaromadendrene (11.6\%) and Copaene (6\%) were identified in PGM extract. In addition some other compounds were also found in appropriate concentrations in P. guajava that seemed to have therapeutic roles. The antitumor activity has been seen in different plants that had secondary metabolites and phytochemicals. This anticancer potential was assumed due to the presence of flavonoids, phenols, flavanols, flavone and alkaloids in medicinal plants 18 . 
The plant derived compounds usually exhibited their antimalignant activity through either suppression of neovascularization or apoptosis ${ }^{19}$. The ideal antitumor drugs should be safe and non-toxic to the growth of normal cells in the body. Unfortunately, drugs generally used for the treatment of cancer, not only inhibit the cancerous cells but also have drastic effect on the normal cells' development. Therefore, scientists are continuously in race to find compounds from plants with solid anticancer capability and minor side effects. The extensive work on different parts of guava proved that $P$. guajava contained valuable therapeutic compounds. For instance P. guajava has employed as antioxidant, anti-bacterial, anti-fungal, anti-diarrheal, antihypertensive, leishmanicidal as well as used to treat obesity and Diabetes mellitus ${ }^{20,21}$. Relating to this concern, our current study was focused on the evaluation of anticancerous potential of methanol and chloroform extracts of P. guajava leaves of Sialkot (Punjab), Pakistan origin. The anti-tumor activity ( $\mathrm{IC}_{50}$ ) was pointed out by Braga et al., when alcoholic extract of P. guajava exhibited $15.6 \pm 0.8$ with HeLa cell-lines protocol. In addition, anti-neoplastic activity seen with comparatively high dose of guava extract (acetone)22. However, anticancer potential of methanol and chloroform extracts of Psidium guajava was evaluated through HeLa cell-line proliferation inhibition protocol. The results indicated that both extracts exhibited excellent anticancer activity when compared with other studies. Even better response of HeLa cells inhibition around 81\% was observed with $200 \mu \mathrm{g}$ of PGM and PGC showed $91 \%$ better than doxorubicin which exhibited $73 \%$ suppression.

\section{CONCLUSION}

In conclusion the anti-tumor activity of methanol and chloroform extracts of Psidium guajava was primarily due to the presence of potent mediators in extracts. These mediators and phytochemical compounds have identified through GC-MS and phytochemical analysis. It was also concluded that HeLa cell-lines suppressive activity of PGM and PGC extracts was progressively amplified with increasing dose of extracts and at appropriate dose showed a significant response on comparison to other data. The PGC effect was found comparatively better than PGM regarding inhibition of cell-lines. As concerned the toxicity of recommended extracts on healthy cells, determined safe after giving $750 \mathrm{mg} / \mathrm{mL}$ dose to healthy rats. Further studies would also be required for the isolation and identification of active compounds from leaves of $P$. guajava, which aggressively involved in anti-cancerous activity.

\section{ACKNOWLEDGEMENT}

I am keenly thankful to Professor Dr. Muhammad Tayyab Ansari, Department of Pharmaceutical Chemistry, Bahauddin Zakariya University, Multan, Pakistan, for the sustain supervision to made this goal successful. Warmly thanks to Prf. Dr. Saeed ul Hassan, M. Nadeem Alvi and Musharraf Abbas Bhatti to facilitate the execution of research activities.

\section{CONFLICT OF INTEREST}

The authors declared no any conflict of interest.

\section{REFERENCES}

1. Lemmens R, Schmelzer G and Van VJ. Position and future of medicinal plants: some reflections. Journal of Tropical Medicinal Plants, 2001; 7(1):56-71.

2. Gutiérrez RMP, Mitchell S and Solis R.V. Psidium guajava: a review of its traditional uses, phytochemistry and pharmacology. Journal of ethnopharmacology, 2008; 117(1):1-27.

3. Sohafy El et al: Quantification of flavonoids of Psidium guajava $\mathrm{L}$. preparations by Planar Chromatography (HPTLC). Pharmacognosy magazine, 2009; 5(17):61-65.

4. Metwally A et al: Phytochemical investigation and antimicrobial activity of Psidium guajava L. leaves. Pharmacognosy magazine, 2010; 6(23):212-217.

5. Jemal A et al: Global cancer statistics. CA: a cancer journal for clinicians, 2011; 61(2): 69-90.

6. Cai $\mathrm{Z}$ et al: Anti-tumor and immunomodulating activities of a polysaccharide from the root of Sanguisorba officinalis L. International journal of biological macromolecules, 2012; 51(4):484-488.

7. Chen X et al: Antitumor and immunomodulatory activity of polysaccharides from Sargassum fusiforme. Food and Chemical Toxicology, 2012; 50(3-4):695-700.

8. Wang J, Wicker LS and Santamaria P. IL-2 and its high-affinity receptor: genetic control of immunoregulation and autoimmunity. in Seminars in immunology. 2009. Elsevier.

9. Ding $X, Z$ hu $F$ and Gao S. Purification, antitumour and immunomodulatory activity of water-extractable and alkaliextractable polysaccharides from Solanum nigrum L. Food chemistry, 2012; 131(2):677-684.

10. Tare $\mathrm{H}$ et al: Comparative hemintholytic potential of extracts obtained from Cymbopogon citratus and Wrightia tinctoria leaves. International Journal of Pharma and Biosciences, 2011; 2(1):321-326.

11. El-Olemy MM, Al-Muhtadi F.J and Afifi AFA. Experimental phytochemistry: A laboratory manual King Saud University Press,1994; 1(1):10-13.

12. Uroos M et al: Nyctanthes arbor-tristis ameliorated FCA-induced experimental arthritis: a comparative study among different extracts. Evidence-Based Complementary and Alternative Medicine, 2017; 5(1):1-13.

13. Atta-ur-Rhman $\mathrm{CM}$ and Thomsen W. Bioassay Technique for Drug Development. Harwood Academic Publishers, 2001 P 3438.

14. Suresh K. Antimicrobial and Phytochemical Investigation of the Leaves of Carica papaya L, Cynodon dactylon L, Psidium guajava L. Ethnobotanical Leaflets, 2008; (1):157-159.

15. Quintans-Júnior $\mathrm{L}$ et al: Antinociceptive action and redox properties of citronellal, an essential oil present in lemongrass. Journal of medicinal food, $2011 ; 14(6): 630-639$.

16. Balde ES et al: Investigations of fungal secondary metabolites with potential anticancer activity. Journal of natural products, 2010; 73(5):969-971.

17. Lu JJ et al: Quinones derived from plant secondary metabolites as anti-cancer agents. Anti-Cancer Agents in Medicinal Chemistry (Formerly Current Medicinal Chemistry-Anti-Cancer Agents), 2013; 13(3):456-463.

18. Al-Dhubiab BE. Pharmaceutical applications and phytochemical profile of Cinnamomum burmannii. Pharmacognosy reviews, 2012; 6(12):125-129.

19. Alam $M$ et al: Evaluation of antitumor effects of the aerial parts of polygonum viscosum L. Glob J Pharmacol, 2014; 8(1):47-52.

20. Abbas B and Fatima T. Evaluation of antibacterial and antifungal activities of Cymbopogon citratus \& Psidium guajava from sialkot origin. Evaluation, 2018; 1:155-163.

21. Braga TV et al: Antioxidant, antibacterial and antitumor activity of ethanolic extract of the Psidium guajava leaves. American Journal of Plant Sciences, 2014; 5(23):3492-3496.

22. Bontempo $\mathrm{P}$ et al: Psidium guajava L. anti-neoplastic effects: induction of apoptosis and cell differentiation. Cell proliferation, 2012; 45(1):22-31. 